\title{
Comparative phylogenetic methods and the cultural evolution of medicinal plant use
}

Article

Accepted Version

Teixidor Toneu, I., Jordan, F. M. and Hawkins, J. (2018) Comparative phylogenetic methods and the cultural evolution of medicinal plant use. Nature Plants, 4. pp. 754-761. ISSN 2055-0278 doi: https://doi.org/10.1038/s41477-018-0226-6 Available at https://centaur.reading.ac.uk/78048/

It is advisable to refer to the publisher's version if you intend to cite from the work. See Guidance on citing.

To link to this article DOI: http://dx.doi.org/10.1038/s41477-018-0226-6

Publisher: Nature Publishing Group

All outputs in CentAUR are protected by Intellectual Property Rights law, including copyright law. Copyright and IPR is retained by the creators or other copyright holders. Terms and conditions for use of this material are defined in the End User Agreement.

www.reading.ac.uk/centaur

\section{CentAUR}


Central Archive at the University of Reading

Reading's research outputs online 


\title{
Comparative phylogenetic methods and the cultural evolution of medicinal plant use
}

\author{
Irene Teixidor-Toneu ${ }^{1,2}$, Fiona M. Jordan ${ }^{3}$, and Julie A. Hawkins ${ }^{1 *}$ \\ ${ }^{1}$ University of Reading, School of Biological Sciences, Harborne Building, Whiteknights Campus, \\ Reading, Berkshire, UK RG6 6AJ \\ ${ }^{2}$ Universitetet i Oslo, Naturhistorisk Museum, Sars' gate 1 Oslo, NO 0562. \\ ${ }^{3}$ University of Bristol, Department of Anthropology \& Archaeology, 43 Woodland Rd, Bristol, UK BS8 \\ $1 U U$
}

*Author for correspondence, j.a.hawkins@reading.ac.uk

\begin{abstract}
Human life depends on plant biodiversity, and the ways in which plants are used are culturally determined. Whilst anthropologists have used phylogenetic comparative methods (PCMs) to gain an increasingly sophisticated understanding of the evolution of political, religious, social, and material culture, plant use has been almost entirely neglected. Medicinal plants are of special interest because of their role in maintaining people's health across the world. PCMs in particular, and cultural evolutionary theory in general, provide a framework in which to study the diversity of medicinal plant applications cross-culturally, and to infer changes in plant use through time. These methods can be applied to single medicinal plants as well as whole pharmacopoeias, and they account for the non-independence of data when testing for ecological or cultural drivers of plant use. With cultural, biological, and linguistic diversity under threat, gaining a deeper and broader understanding of the variation of medicinal plant use through time and space is pressing.
\end{abstract}

\section{Introduction}


Plants are essential for human life and culture. They are used as food, fodder, medicines, and a vast array of craft and building materials, in ways determined by both plant biology and culture. Throughout history, plant diversity shaped cultural practices, and in turn, humans shaped plant diversity by domesticating and translocating plant species, or causing them to go extinct. Diverse wild and cultivated plant species have a high impact on societies' well-being by providing healthcare [1]. Here we propose a cultural macroevolutionary framework to study the use of plants in ethnomedicine. Anthropologists have used phylogenetic comparative methods (PCMs) to gain increasingly sophisticated understanding of the evolution of various aspects of culture. Despite a wealth of data in ethnobotanical and ethnographic literature, and recognition of the role of cultural identity in medicinal plant species preferences [2-6], PCMs have hardly yet been applied to understand cultural diversity in medicinal plant use. Current rates of biological and cultural diversity loss are threatening ecosystems as well as human well-being [7]. Simultaneously, intangible cultural heritage including knowledge about medicinal plants is quickly being lost to acculturation (for example, [8-10]). This rapid change makes studies capturing the relationship between cultural evolution and plant use particularly timely. These approaches are also readily realisable for the first time, using the large-scale databases that integrate language phylogenies with cultural, environmental, and ecological data now readily and freely available [11]. In this Perspectives article, we outline how questions relating to the transmission of medicinal plant use and knowledge are particularly amenable to PCMs, considering individual plant species and plants as components of whole ethnopharmacopoeias.

Biologists explain the origins and maintenance of trait differences amongst lineages of organisms using phylogenetic comparative methods (PCMs) [12]. To do this, they use phylogenies to estimate species relationships, usually based on DNA sequence data. Combined with morphological, physiological, behavioural, or other trait data that is mapped onto the ensuing evolutionary trees, hypotheses about the patterns and processes of trait evolution can be tested [13]. Increasingly, anthropologists interested in cultural macroevolutionary processes are using PCMs to understand the history of human populations and the dynamics of cultural traits. In anthropology, the phylogenetic relatedness of ethnolinguistic groups is inferred through analysis of linguistic (rather than genetic) data, and the distribution of cultural traits is investigated [14-17]. Human populations (cultures, languages, societies) are phylogenetically non-independent, a fact recognised as "Galton's Problem" in cross-cultural studies for over 100 years [18]. The adoption of PCMs as tools for crosscultural analysis [19] has allowed for the robust statistical accounting for shared history, and these methods have significantly advanced understanding of the origins and diversification of political, religious, social, and material culture [10-20]. Just as in the biological sciences, a multiplicity of PCMs 
are applied in anthropology and linguistics to determine whether traits have multiple origins, whether pairs of traits are co-evolving, to infer ancestral states, and to characterise the mode and tempo of trait evolution; traits can also be mapped in space, suites of traits considered for their joint dynamics, and correlations with environmental variables explored [11, 21-24].

The few uses of PCMs to understand how elements of biodiversity are differently exploited crossculturally have focused on plant-based subsistence traits. Mace and Jordan [25] included the presence or absence of grain, root/tuber, or tree crops in a wider study of the role of ancestry and geographic proximity in the diversification of Austronesian cultures, and found that when controlling for relatedness, geographical proximity predicted whether societies shared crop types. Currie and Mace [26] used PCMs to infer the relative evolutionary rates of cultural change, showing that crop type was an averagely-changing cultural feature across both Austronesian and Bantu societies. Although focussing on species rather than life forms when using PCMs for cross-cultural comparison is challenging, the potential for better understanding cultural and plant use evolution is enormous. Here we explore three main applications of PCMs, the first two using phylogenetic relatedness of ethnolinguistic groups to explore the origins and evolutionary relationships of ethnobotanical features, and the third exploring the drivers of overall similarity in ethnofloras (Table 1). Mapping and ancestral reconstructions of features (Table $1 \mathrm{~A}$ ), such as the use of specific plants, allows us to examine cultural change while accounting for Galton's problem. In terms of the use of specific plants, at the heart of such study is the question "is shared plant use homologous"? In this Perspectives article we explore the concept of homology, showing how it can usefully be applied to better understand the use of plants in medicine. The second application explores correlated evolution (Table 1B). Here we consider how explicit tests of co-evolution of ethnobotanical features might permit deeper understanding of the wider context of plant use. The third application uses methods that consider the relatedness of the whole ethnoflora (Table 1C), opening new lines of investigation into the drivers of the phylogenetic composition of ethnofloras. Environmental data are of particular interest as potential drivers, for example, vegetation type has long been suggested as a factor shaping the composition of ethnopharmacopoeias [27]. Therapeutic needs, expected to drive plant use, might also co-vary with some environmental parameters. High resolution environmental data are used increasingly by evolutionary anthropologists to determine the role of ecology as a drivers of cultural practices [11]. Whether focusing on single plant species and using the methods for testing for correlated evolution (Table 1B) or methods for assessing the drivers of the composition of whole ethnofloras (Table 1C), wider application of PCMs to ethnobotanical and environmental data has potential for fruitful, new research directions. 


\section{Macroevolutionary studies and medicinal plant use}

Macroevolutionary studies explore evolutionary processes occurring at time scales far exceeding the human lifespan, based on the observation of patterns observed above the level of the species. In contrast, microevolutionary studies are of adaptive processes that can be observed in nature or the laboratory [28]. Our proposal to use PCMs in the study of medicinal plants borrows techniques of macroevolutionary biology that are also applied by evolutionary anthropologists. These PCMs complement established "microevolutionary" observations of medicinal plant use. For example, processes of botanical knowledge adaptation have been studied in depth among migrant populations, who adopt both conservative and innovative strategies by importing plant species from their home environments as well as using plants from the new flora (see for example, [29-33]). Innovation through the incorporation of individual plants sourced through cultural exchange and trade (for example, plants traded from Asia to the Mediterranean [34]) are observed adaptations. Textual evidence can also provide insights into transmission or adaptation of knowledge at the timescale of written records. For example, comparison of historical materia medica with more contemporary texts or records can identify plant-use combinations that have experienced "mutation" and "selection" [35], with the caveat that the texts themselves shape the use of the plant-based medicines [36]. Increasingly, researchers are studying the transmission of medicinal plant use knowledge within communities using the social learning strategies identified by cultural microevolutionary theorists [35,37-40].

It has been suggested that some medicinal uses of specific plants may be based on prolonged experimentation of a society in a particular location, reflecting long-term and relatively static interaction with the floristic environment [41]. The possibility that long-term vertical transmission of knowledge might be on the timescale at which ethnolinguistic groups diverge raises questions that are resonant with those evolutionary anthropologists have asked regarding the evolution of other cultural traits. Nonetheless, PCMs have only recently been suggested as means to understand the origins of the use of specific species and to determine whether or not knowledge about plant uses is inherited, culturally diffused, or independently adopted by different societies [42]. PCMs would allow researchers to systematically address questions about cross-cultural diversity and changing medicinal plant knowledge at the timescale at which ethnolinguistic groups diverge, and in the absence of textual evidence.

\section{Research directions}

\subsection{Is shared plant use homologous?}


Similarity due to shared ancestry is referred to as homology in biological systematics [43]. Despite the diversity of applications of phylogenetic methods in evolutionary anthropology [44], conceptual issues surrounding homology have largely been the concern of archaeologists and scholars inferring phylogenetic trees from material culture such as tool technologies [45-46]. In the 20th century anthropologists such as Steward [47] articulated criteria for homologous cultural traits such as geographic proximity, quantity of shared traits, and uniqueness, but these suggestions were not taken forward in hypothesis-testing frameworks. We suggest that combining the rich literature from biological sciences describing how hypotheses of homology are tested, with the concerns articulated by cultural evolutionary archaeologists, provides a useful approach to consider the relationship between different sources of evidence.

For biological structures, similarity and congruence tests are used to differentiate parallelism, convergence and homology [43, 48-50]. The similarity test for structures is based on observations of topographic (positional) correspondence and ontogenetic (developmental and compositional) similarity. The congruence test describes whether an attribute has a single origin in a phylogeny (is congruent, or homologous), or multiple origins (is incongruent, or not homologous). If homology is continuity of form, then continuity must be positional (e.g. the structures found to be homologous must all be in the axis of a leaf), ontogenetic/compositional (e.g. the structures found homologous are all spiny, resulting from the hardening and senescence of an axillary shoot) and phylogenetic (e.g. the homologous structures are shared, derived characters, or markers of a clade that have axillary spines as a defining feature).

Even though there are important disanalogies between cultural and biological processes [16, 51], multiple sources of evidence could also be incorporated in studies of medicinal plants, and relations differentiated depending on multiple tests. When species are used medicinally across cultures there are at least four sources of evidence, aside from written records and examination of historical and archaeological collections, which are informative of the origins of plant use (Table 2). We suggest here how ancestry (vertical transmission), independent discovery (convergence) and cultural diffusion (horizontal transmission) might be characterised by linguistic, geographic and use tests, whilst ultimately a congruence test using an explicit phylogenetic framework provides evidence of historical continuity.

Firstly, by analysing sets of plant names, historical linguistics may provide evidence of the phylogenetic and therefore temporal depth of plant use or knowledge [52]. Historical linguists refer to linguistic homology as cognacy: cognates are words that share form and meaning due to common descent. Reconstructions of the phylogenetic depth of cognates across ethnolinguistic groups are commonly applied in studies of translocated plant species, typically domesticates [53-55], but 
sometimes other culturally, ecologically, or economically important species $[52,56,57]$. This method is not a single diagnostic test, as closely-related languages can independently innovate terms that are similar in form and meaning while not sharing a descent relationship ([58]:22), and unless applied with caution, historical linguistic reconstruction can attribute greater time depth than warranted when words have been borrowed [59]. Secondly, aspects of plant use can be used as a source of evidence. Usage encompasses the parts of the plants used, the modes of preparation, and the modes of administration or application, each per therapeutic application. Medicinal applications are described both by standard scientific use categories and by the emic rationale (i.e., culturally meaningful categories [60]). For example, the emic category of asumid or "cold" used among Amazigh communities in Morocco encompasses ailments ranging from the musculoskeletal, gynaecological and respiratory etic categories [61]. The similarities and differences of how plants are prepared and administered, and for what end, will therefore contribute to understanding of historical plant use. Moreover, a plant may be used across multiple cultural domains beyond healing such as religion, textiles, and diet. The variation in the breadth of use of a plant across cultural domains can also be indicative of a shared source of knowledge between different societies, whether ancestry or cultural diffusion. Thirdly, accounting for peoples' geographical distribution and trading relationships is important, since direct horizontal transmission is possible between distantly related cultures only if they are in proximity [62] or have established trade relationships [34,63]. Finally, phylogeny to account for cultural relatedness is an important test since shared ancestry is an explicit indicator of vertical transmission. The existence of inference of plant use in ancestral communities ("proto-languages" on language phylogenies) can indicate whether shared use predates divergence of those ethnolinguistic groups.

Our scheme supposes that ancestral use is characterised by the use of cognate plant names, and similar therapeutic applications and modes of use, among linguistically related societies. Linguistic and use tests may not be sufficient to determine ancestry, since both names and specific plant uses may change through time despite continuity of use. Considering one pair of ethnolinguistic groups in Mesoamerica, Lowland Mixe and Zoque-Popoluca, Leonti et al [64] found nine cognate names for 123 shared medicinal plants, of which 62 had a similar usage, suggesting relatively rapid linguistic divergence. As case studies accumulate, the frequency of linguistic divergence or divergence in uses can be estimated when phylogenetic tests are indicative of ancestral use (Figure 1). Linguistic divergence could differ between different categories of plant use: Chirkova et al [65] considered five Chinese ethnolinguistic groups, using plant names to corroborate hypotheses of ethnolinguistic relatedness. They found shared plant names were most common for plants with ritual use, or those with low cultural significance (plants that were not field crops, fruit trees or used as fodder, food, 
fuelwood or in medicine or ritual). The former pointed to sharing of ritual practices, the latter was interpreted as borrowing of names from the indigenous language for items of acculturation encountered on migration since the local ethnic groups were "newcomers" in the area [65]. In another study suggesting phylogenetic distribution of cognate plant names might be indicative of migration history Bostoen et al [52] used a phylogeny of Bantu languages to explore the names of plants characteristic of forest environments in order to infer historical occupations of forested environments. Linguistic and use tests may be of particular value when the phylogenetic test is suggestive of independent discovery or cultural diffusion. Linguistic tests may distinguish independent discovery from cultural diffusion, since the latter can be characterised by the use of loanwords [66-67], whereas therapeutic applications and modes of application of a species might converge in the case of independent discovery.

The use of PCMs in cultural anthropology has been critiqued by those arguing that cross-cultural diffusion or rapid adaptation may invalidate the use of tree-based, hierarchical methods $[51,68]$. The validity of these critiques depend on the timescale of cultural evolution under consideration, the nature of the research question (in the absence of very rich textual data, inferring ancestral traits and determining models of trait evolution are only possible using phylogenies), and the nature of the traits themselves $[16,23]$. Accounting for variance imposed by hierarchical population structure is critical for any investigation of cultural diversity, whether with PCMs or standard multilevel modelling methods. Using explicit phylogenetic hypotheses (or Bayesian posterior sample of phylogenies) formalises the identification of independent evolutionary events and of horizontal transmission itself [25]. Furthermore, simulation studies such as Greenhill et al [69] and Nunn et al [70] show that the statistical impact of borrowing and diffusion depends on the global versus local nature of the borrowing. "Local" borrowing between sister populations-in principle the most common kind-should not invalidate tree-based methods [69]. An explicit phylogenetic framework opens up the possibility of a synthetic, macro-scale research programme that documents the extent to which there are global patterns in dissociation of names and uses, identifying drivers of dissociation where plant species have apparently ancestral use in medicine.

\subsection{Are aspects of medicinal plant use correlated?}

PCMs were originally developed to test adaptationist ideas, and can help tackle several key questions about the co-evolution of material and immaterial aspects of plant use. These include the definition of illnesses treated (for example, classified according to their aetiology) [71] and techniques associated with herbal practice (such as preparation and application modes), in addition to co-variation in the plant materials themselves (floristic composition of the ethnopharmacopoeias $[72,73])$. For example, the choice of therapy, therapist, and therapeutic application of plants may be 
determined by beliefs around symptomatology and aetiology [6, 74-77]. Furthermore, Vossen et al [33] and Teixidor-Toneu et al [76] observed in disparate study sites (South America and North Africa) that treatment systems and illness aetiologies seem to be more conserved than treatment materials themselves, but hypotheses regarding differential change through time of aspects of medical systems have yet to be formally tested.

PCMs explicitly testing for correlated evolution might also consider which plant species have shared histories. Borrowing the idea that cultures may have "core traditions" and "peripheral elements" [68], ethnopharmacopoeias may have medicinal plants (or sets of plants) mostly transmitted vertically, while others are readily shared across cultures. In the context of conservation biology in Southeast Asia, Ellen and Puri [78] identify a "core" of medicinal plants in ethnopharmacopoeias that represent a shared ethnomedicinal tradition across societies. However, whether elements of ethnopharmacopoeias are transmitted individually or sets of plants share cultural histories is yet to be tested. Where ethnolinguistic phylogenies are used as the framework for hypothesis testing, it becomes possible to estimate the degree of vertical (ancestor-descendant) versus horizontal (diffusion) transmission or independent innovation [51], since these might differ between different component characteristics of items of (material) culture [79]. Ideally, the aim is for wider tests of Borgerhoff Mulder et al's [51] supposition that most traits will exhibit a combination of horizontal and vertical transmission, with horizontal transmission dominating at some times and vertical transmission at others [69], where species or plant lineages are the traits of interest.

\subsection{Measuring and accounting for similarities between whole pharmacopoeias}

Beyond exploring the cultural histories of specific medicinal plants or remedies, ethnopharmacopoeias or medicinal floras can be studied as a whole. Ethnobotanists have used a range of quantitative measures to compare pharmacopoeias across societies: from directly scoring the number of shared species $[78,80]$ to using biological diversity measures such as the Jacquard Index [81] or consensus analysis indices [82-84]. However, these measures are limited by the degree of overlap between the floras compared. Since plants are phylogenetically related to each other, community phylogenetic methods overcome this limitation and allow for comparisons at any taxonomic level [5, 85-87]. They are justified because closely related plants are chemically similar and may have the same pharmacological properties $[88,89]$. The use of a plant species in one ethnopharmacopoeia but a related species in another may represent real similarity in ethnofloristic composition. Community phylogenetic measures allow for this similarity to be reflected in comparative measures, opening up the possibility of broader or even global studies of ethnofloristic relatedness. Such an approach could also be useful to overcome some methodological limitations with PCMs. Current methods allow us to study the dynamics of single traits or coevolving pairs, but 
are not yet capable of comparing the multiple species combinations present in ehtnopharmacopoeias.

In the first study to use a linguistic phylogeny to represent cultural ancestry and a phylogenetic measure of the similarities of ethnopharmacopoeias, Mantel tests were used to explore whether relatedness of ethnofloras was correlated with cultural relatedness [5]. The study also considered the effects of: geographic proximity, assessing potential for cultural diffusion; floristic environment, considering the environmental affordances; and similarity due to shared linguistic ancestry, addressing Galton's problem. An important caveat of studies evaluating multiple traits is the risk of over interpreting $p$-values in terms of strength of evidence for a particular pattern, or refuting null hypotheses [51]. Indeed, Saslis-Lagoudakis et al [5] highlighted the significant impact of floristic environment, though ancestry also showed a positive correlation with the composition of the ethnopharmacopoeia. Teasing apart the species, plant lineages or uses that are inherited via different transmission channels or at different rates is a step-up in analytical complexity, but new hybrid model selection approaches that incorporate phylogenetic structure into multi-model inferences may provide appropriate tools.

One important caveat when considering applications of this kind is that the recognition of what constitutes the set of medicinal plants for any ethnolinguistic group may be problematic.

Compilations from literature, or data from focussed fieldwork, may include plant species that are widely and frequently used along with species that perhaps have only one known use report. Where PCMs are applied to single plant species or aggregates of species, to investigate homology of use or features correlated with use, then conflating important with less important species would not influence the outcome of the analysis. However, where a whole ethnoflora is under consideration, and quantitative measures of the similarity between ethnofloras are made, metrics may be strongly influenced by whether or not rarely used plant species are included. This issue was explored by Souza et al. [90], who developed weighted metrics to take into account the number of use reports for any species. Approaches of this kind address the problem of rarely-used species being inconsistently recorded.

\section{Implementation challenges}

\subsection{Floristic and ethnofloristic considerations}

Floristic checklists are needed to explicitly consider the role of the floristic environment on medicinal plant use, and floristic composition is explicitly a variable when considering whole floras. Analyses of the depth and origin of specific plant remedies will always be constrained by the distribution of the 
plants, whether naturalised, native, or imported, making floristic checklists and distribution maps necessary. The definition of a plant's area of distribution will depend on the species or ethnospecies definition used, at least for some herbal remedies. Primary information on medicinal plant use is collected in emic terms, and the definition of plant species used by individuals in culture-specific ways do not always correspond one-to-one with scientific botanical species [91]. A vernacular plant name can be used for more than one botanical species, or alternatively, a single botanical species can represent more than one ethnospecies [91]. Although this is a caveat that remains mostly unacknowledged in ethnobotanical comparative studies, it is central to the analyses proposed here. One herbal remedy can maintain its vernacular name and use across a broad area, but refer to different botanical species with reduced areas of distribution [92]. Whilst it is not possible to meaningfully take this into account in comparative studies of whole pharmacopoeias based on phylogenetic relationships between plants, analyses of individual plants or remedies should critically define and justify one or other approach.

\subsection{Data availability}

Anthropology and linguistics are undergoing their own "informatics" revolution, and recent advances have made the construction and availability of large data resources widespread [20]. eHRAF [93], D-PLACE [11], Glottolog [95], Seshat [95], and various initiatives from the Glottobank and CLLD consortia [96] make cultural and linguistic data more accessible than ever. In particular, language phylogenies for at least ten large and widely geographically spread families are readily available from D-PLACE [11], including Indo-European, Bantu, and Austronesian. Phylogenetic linguistics is a fast growing field, and new language family trees, derived by cutting-edge Bayesian phylogenetic inference, emerge regularly. In contrast, the systematic availability of corresponding ethnobotanical field data may be a major limitation.

No compilation of medicinal plant uses across the globe is available and ethnobotanical data is dispersed in multiple separate publications. Documentation efforts are extensive in some areas and partial or almost non-existent in others [97, 98]; absence of data may be a result of absence of fieldwork in a particular region. On the one side, trustworthy botanical identifications are required [99-100]; on the other, ethnobotanical data may have been collected by scholars from different disciplines with different aims, which may result in biased views of local medical systems. For example, ethnopharmacological accounts are notorious for not giving enough context of the medical practices in which therapeutic materials are used, and lists provided may be restricted to a group of organisms $[73,78,101]$. Efforts are being made to set methodological guidelines and data standards, increasing the quality ethnobotanical and ethnomedicinal data collection and providing quality criteria for the selection of literature $[60,101]$. Meanwhile, for some applications where whole 
ethnopharmacopoeias are considered, it might be appropriate to use large data sets compiled using data from herbarium vouchers to complement the ethnobotanical literature [102].

Databases of medicinal plant uses are proposed as tools for cross-checking contemporary ethnopharmacological field-data and as repositories for data mining [103]. For these repositories to be most useful, they should include information about plant users, therapeutic context in which plants are used, emic descriptions of illness, illness aetiologies, and plant species' vernacular names (and language), in addition to data on plant parts used, therapeutic application, preparation, and mode of application. Such information should be gathered systematically and be compatible with other complementary cultural and linguistic large data resources (including [11, 94, 95]).

\section{Significance and conclusions}

This review highlights the potential of PCMs in particular, and cultural evolutionary theory in general, to address interdisciplinary questions about the variation and history of medicinal plant use. Whilst there is copious evidence for recent exchange and innovation of plant use that may lead to cross-cultural similarities (of which recent migrations are clear examples of transmission of knowledge), any historically deep medicinal plant use remains an assumption that in the absence of textual evidence can only be tested using PCMs. We have proposed a test combining four sources of evidence to distinguish homology (ancestral use) from cultural diffusion and independent discovery of plant uses. We have further explored the ways in which cultural evolutionary theory can be applied to questions of variation and transmission of knowledge about biodiversity. Finally, we highlight sources of data as well as data gaps and suggest a strategy for systematic data collection, necessary for further analysis.

This review has focused on medicinal plants due to their importance for human well-being. However, this approach can inform other key related fields such as food provisioning. A test for ancestry and independent discovery of medicinal plant uses may be of particular value when aiming to identify pharmacologically active plants, but understanding the mechanisms behind the inheritance and diffusion of used plant diversity has much broader applications. Such meta-analyses are pressing due to the trends of loss of both biological and cultural primary data, and could help identify areas where more data are needed. Importantly, results could provide clues for the conservation of intimately linked biological and cultural systems.

\section{Acknowledgements}


We would like to thank $\operatorname{Dr}$ Anneleen Kool for helpful discussions during the preparation of this manuscript. Figure 1 icons made by Freepik, Smashicons, and Roundicons from www.flaticon.com.

\section{Data accessibility}

This article has no additional data.

\section{Author's contributions}

I.T.-T., F.M.J and J.A.H conceived the ideas. J.A.H. led the writing of the manuscript. All authors contributed critically to writing and gave their final approval for publication.

\section{Competing interests}

We have no competing interests.

\section{Funding}

I.T.-T. and J.A.H received funding from the European Union's Seventh Framework Programme for research, technological development and demonstration under the Grant agreement no. 606895. F.M.J was supported by the European Research Council's Horizon 2020 research and innovation programme under Starting Grant no. 639291.

\section{References}

[1] WHO World Health Organisation 2013 WHO traditional medicine strategy: 2014-2023. Geneva, World Health Organisation.

[2] De Boer H. J., Lamxay V. 2009 Plants used during pregnancy, childbirth and postpartum healthcare in Lao PDR: A comparative study of the Brou, Saek and Kry ethnic groups. J. Ethnobiol. Ethnomed. 5:25. (doi:10.1186/1746-4269-5-25)

[3] Menendez-Baceta G., Aceituno-Mata L., Reyes-García V., Tardío J., Salpeteur M., Pardo-deSantayana M. 2015 The importance of cultural factors in the distribution of medicinal plant knowledge: A case study in four Basque regions. J. Ethnopharmacol. 161, 116-127.

[4] Quave C. L., Pieroni A. 2015 A reservoir of ethnobotanical knowledge informs resilient food security and health strategies in the Balkans. Nature Plants 1:14021.

(doi:10.1038/NPLANTS.2014.21)

[5] Saslis-Lagoudakis C. H., Hawkins J. A., Greenhill S. J., Pendry C. A., Watson M. F., TuladharDouglas W., Baral S. R., Savolainen V. 2014 The evolution of traditional knowledge: Environment shapes medicinal plant use in Nepal. Proc. R. Soc. B. 281: 20132768. (doi:10.1098/rspb.2013.2768)

[6] Shepard G. H. 2004 Sensory ecology of medicinal plant therapy in two Amazonian societies. Am. Anthropol. 106, 252-266.

[7] Maffi L. 2005 Linguistic, cultural and biological diversity. Annu. Rev. Anthropol. 29, 599-617.

[8] Begossi A., Hanazaki N., Tamashiro J. Y. 2002 Medicinal plants in the Atlantic forest (Brazil): Knowledge, use, and conservation. Hum. Ecol. 30, 281-299. 
[9] Geck M. S., Reyes García A. J., Casu L., Leonti M. 2016 Acculturation and ethnomedicine: A regional comparison of medicinal plant knowledge among the Zoque of southern Mexico. J. Ethnopharmacol. 187, 146-159.

[10] Vandebroek I., Reyes-García V., Albuquerque U. P., Bussmann R., Pieroni A. 2011 Local knowledge: Who cares? J. Ethnobiol. Ethnomed. 7: 35. (doi:10.1186/1746-4269-7-35)

[11] Kirby K. R., Gray R. D., Greenhill S. J., Jordan F. M., Gomes-Ng S., Bibiko H.-J., Blasi D. E., Botero C. A., Bowern C., Ember C. R., Leehr D., Low B. S., McCarter J., Divale W., Gavin M. C. 2016 D-PLACE: A global database of cultural, linguistic and environmental diversity. PLOS ONE 11, e0158391. (doi:10.1371/journal.pone.0158391)

[12] Garamszegi L. Z. (ed.) 2014 Modern phylogenetic comparative methods: Concepts and practice. Heidelberg New York Dordrecht London: Springer.

[13] Felsenstein J. 1985 Phylogenies and the comparative method. Am. Nat. 125, 1-15.

[14] Blute M., Jordan F. M. 2018 The evolutionary approach to history: Sociocultural phylogenetics. In The Oxford handbook of evolution, biology, and society (ed. Hopcroft R. J.), pp. 621-642. Oxford, Oxford University Press.

[15] Cornwell W., Nakagawa S. 2017 Phylogenetic comparative methods. Curr. Biol. 27, R333-R336.

[16] Gray R. D., Greenhill S. J., Ross R. M. 2007 The pleasures and perils of Darwinizing culture (with phylogenies). Biol. Theory 2, 360-375.

[17] Mace R., Holden C. J. 2005 A phylogenetic approach to cultural evolution. Trends Ecol. Evol. 20, 116-121.

[18] Tylor E. B. 1889 On a method of investigating the development of institutions applied to the laws of marriage and descent. J. Royal Anthropol. Inst. 18, 245-272.

[19] Mace R., Pagel M. 1994 The comparative method in anthropology. Curr. Anthropol. 35, 549-564.

[20] Gray R. D., Watts J. 2017 Cultural macroevolution matters. Proc. Natl Acad. Sci. 114, 7846-7852.

[21] Botero C. A., Gardner B., Kirby K. R., Bulbulia J., Gavin M. C., Gray R. D. 2014 The ecology of religious beliefs. Proc. Natl Acad. Sci. 111, 16784-16789. (doi/10.1073/pnas.1408701111)

[22] Currie T. E. 2013 Cultural evolution branches out: The phylogenetic approach in cross-cultural research. Cross Cult. Res. 47, 102-130.

[23] Jordan F. M. 2013 Comparative phylogenetic methods and the study of pattern and process in kinship. In Kinship systems: Change and reconstruction (eds. McConvell P., Keen I., Hendery R.), pp. 43-58. Salt Lake City, UT, University of Utah Press.

[24] Levinson S. C., Gray R. D. 2012 Tools from evolutionary biology shed new light on the diversification of languages. Trends Cogn. Sci. 16, 167-173.

[25] Mace R., Jordan F.M. 2011 Macro-evolutionary studies of cultural diversity: A review of empirical studies of cultural transmission and cultural adaptation. Philos. Trans. R. Soc. B. Biol. Sci. 366, 402-411.

[26] Currie T. E., Mace R. 2014 Evolution of cultural traits occurs at similar relative rates in different world regions. Proc. R. Soc. B 281, 20141622. (doi:10.1098/rspb.2014.1622) 
[27] Voeks R. A. 2004 Disturbance pharmacopoeias: MEdicina and myth from the humid tropics. Ann. Assoc. Am. Geogr. 94, 868-888.

[28] Reznick D. A., Ricklefs R. E. 2009 Darwin's bridge between microevolution and macroevolution. Nature 457, 837-842.

[29] Medeiros P. M., Soldati G. T., Alencar N. L., Vandebroek I., Pieroni A., Hanazaki N., Albuquerque U. P. 2012 The use of medicinal plants by migrant people: Adaptation, maintenance, and replacement. Evid. Based Complement. Alternat. Med. 2012: 807452. (doi:10.1155/2012/807452)

[30] Pieroni A., Vandebroek I. 2007 Travelling cultures and plants: The ethnobiology and ethnopharmacy of migrations. New York: Berghahn Books.

[31] Van Andel T., Mitchell S., Volpato G., Vandebroek I., Swier J., Ruysschaert S., Rentería Jiménez C. A., Raes N. 2012 In search of the perfect aphrodisiac: Parallel use of bitter tonics in West Africa and the Caribbean. J. Ethnopharmacol. 143, 840-850.

[32] Volpato G., Godínez D., Beyra A. 2009 Migration and ethnobotanical practices: The case of tifey among Haitian immigrants in Cuba. Hum. Ecol. 37, 43-53.

[33] Vossen T., Towns A., Ruysschaert S., Quiroz D., van Andel T. 2014 Consequences of the TransAtlantic slave trade on medicinal plant selection: Plant use for cultural bound syndromes affecting children in Suriname and Western Africa. PLOS ONE 9, e112345. (doi:10.1371/journal.pone.0112345)

[34] Touwaide A., Appetiti E. 2013 Knowledge of Eastern material medica (Indian and Chinese) in pre-modern Mediterranean medical traditions: A study in comparative historical ethnopharmacology. J. Ethnopharmacol. 148, 361-378.

[35] Leonti M., Staub P. O., Cabras S., Castellanos M. E., Casu L. 2015 From cumulative cultural transmission to evidence-based medicine: Evolution of medicinal plant knowledge in Southern Italy. Front. Pharmacol. 6, 207.

[36] Leonti M. 2011 The future is written: Impact of scripts on the cognition, selection, knowledge and transmission of medicinal plant use and its implications for ethnobotany and ethnopharmacology. J. Ethnopharmacol. 134, 542-555.

[37] Reyes-García V., Broesch J., Calvet-Mir L., Fuentes-Peláez N., McDade T. W., Parsa S., Tanner S., Huanca T., Leonard W. R., Martínez-Rodríguez M. R. 2009 Cultural transmission of ethnobotanical knowledge and skills: an empirical analysis from an Amerindian society. Evol. Hum. Behav. 30(4), 274-285.

[38] Kendal R. L., Boogert N. J., Rendell L., Laland K. N., Webster M., Jones P. L. 2018 Social learning strategies: Bridge-building between fields. TiCS (doi.org/10.1016/j.tics.2018.04.003)

[39] Henrich J., Broesch J. 2011 On the nature of cultural transmission networks: Evidence from Fijian villages for adaptive learning biases. Phil. Trans. R. Soc B 366, 1139-1148.

[40] Albuquerque U. P., Júnior W. S. F. 2017 What do we study in evolutionary ethnobiology? Defining the theoretical basis for a research program. Evol. Biol. 44(2), 206-215.

[41] Moerman D. E., Pemberton R. W., Kiefer D., Berlin B. 1999 A comparative analysis of five medicinal floras J. Ethnobiol. 19, 49-67.

[42] Hawkins J.A., Teixidor-Toneu I. 2017 Defining 'ethnobotanical convergence'. Trends Plant Sci. 22(8), 639-640. 
[43] Patterson C. 1982 Morphological characters and homology. In Problems of phylogenetic reconstruction (eds. Joysey K. A., Friday A. E.), pp. 21-74. Academic Press, London.

[44] Nunn C. L. 2011 The comparative approach in evolutionary anthropology and biology. Chicago, The University of Chicago Press.

[45] Lyman R. L. 2001 Culture historical and biological approaches to identifying homologous traits. Style and Function: Conceptual Issues in Evolutionary Archaeology, Bergin and Garvey, Westport CT, 69-89.

[46] O’Brien M. J., Lyman R. L. 2000 Applying evolutionary archaeology: A systematic approach. New York, Kluwer Academic / Plenum Publishers.

[47] Steward J. H. 1929 Diffusion and independent invention: A critique of logic. Am. Anthropol. 31, 491-495.

[48] Patterson C. 1988. Homology in classical and molecular biology. Mol. Biol. Evol. 5, 603-625.

[49] De Pinna M. G. G. 1991 Concepts and tests of homology in the cladistic paradigm. Cladistics 7, 367-394.

[50] Hawkins J. A., Hughes C. E., Scotland R. W. Primary homology assessment, characters and character states. Cladistics 13, 275-283. (doi:10.1111/j.1096-0031.1997.tb00320.x)

[51] Borgerhoff Mulder M., Nunn C. L., Towner M. C. 2006. Cultural macroevolution and the transmission of traits. Evol. Anthr. 15(2), 52-64.

[52] Bostoen K., Grollemund R., Muluwa J. K. 2013 Climate-induced vegetation dynamics and the Bantu Expansion: Evidence from Bantu names for pioneer trees (Elaeis guineensis, Canarium schweinfurthii, and Musanga cecropioides). C. R. Geosci. 345, 336-349.

(doi:10.1016/j.crte.2013.03.005)

[53] Perrier X., De Langhe E., Donohue M., Lentfer C., Vrydaghs L., Bakry F., Carreel F., Hippolyte I., Horry J.-P., Jenny C., Lebot V., Risterucci A.-M., Tomekpe K., Doutrelepont H., Ball T., Manwaring J., de Maret P., Denham T. 2011 Multidisciplinary perspectives on banana (Musa spp.) domestication. Proc. Natl Acad. Sci. 108(28), 11311-11318.

[54] Fuller D. Q., Madella M. 2009 Banana cultivation in South Asia and East Asia: A review of the evidence from archaeology and linguistics. ERA 7, 333-351.

[55] Fuller D. Q., Boivin N., Hoogervorst T., Allaby R. 2011 Across the indian ocean: The prehistoric movement of plants and animals. Antiquity 85, 544-558. (doi:10.1017/\$0003598X00067934)

[56] Fuller R. J. M. 2009 Using historical linguistics to describe Polynesian ethnomycology. Econ. Bot. 63, 388-396.

[57] Rangan H., Bell K. L., Baum D. A., Fowler R., McConvell P., Saunders T., Spronck S., Kull C. A., Murphy, D. J. 2015 New genetic and linguistic analyses show ancient human influence on Baobab evolution and distribution in Australia. PLoS ONE 10, e0119758. (doi:10.1016/j.crte.2013.03.005)

[58] Dixon R. M. W. 2002 Australian languages: Their nature and development. Cambridge, Cambridge University Press.

[59] McMahon A., McMahon R. 2000 Problems of dating and time depth in linguistics and biology. In Time Depth in Historical Linguistics Vol. 1 (eds. McMahon A., Renfrew C., Trask L.), pp. 59-73.

Cambridge, McDonald Institute for Archaeological Research. 
[60] Heinrih M., Lardos A., Leonti M., Weckerle C., Willcox M., ConSEFS advisory group. 2018 Best practice in research: Consensus Statement on Ethnopharmacological Field Studies - ConSEFS. J. Ethnopharmacol. 211, 329-339.

[61] Teixidor-Toneu I., Martin G. J., Ouhammou A., Puri R. K., Hawkins J. A. 2016 An ethnomedicinal survey of a Tashelhit-speaking community in the High Atlas, Morocco. J. Ethnopharmacol. 188, 96110.

[62] Lacuna-Richman C. 2006 The use of non-wood forest products by migrants in a new settlement: Experiences of a Visayan community in Palawan, Philippines. J.Ethnobiol. Ethnomed. 2:36. (doi.org/10.1186/1746-4269-2-36)

[63] Beheim B. A., Bell A. V. 2011 Inheritance, ecology and the evolution of canoes of east Oceania. Proc. R. Soc. B 278, 3089-3095.

[64] Leonti M., Sticher O., Heinrich M. 2003 Antiquity of medicinal plant usage in two Macro-Mayan ethnic groups (México). J. Ethnopharmacol. 88, 119-124.

[65] Chirkova K., Huber F. K., Weckerle C. S., Daudey H., Pincuo G. Plant names as traces of the past in Shuiluo valley, China. J. Ethnobiol. 36, 192-214. (doi:10.2993/0278-0771-36.1.192)

[66] Bowern C. 2007 On eels, dolphins, and echidnas: Nyulnyulan prehistory through the reconstruction of flora and fauna. Verba Docenti: Studies in Historical and Indo-European Linguistics, edited by A. Nussbaum, 39-53.

[67] Haspelmath M. 2009 Lexical borrowing: Concepts and issues. In Loanwords in the world's languages: A comparative handbook (eds. Haspelmath M., Tadmor U.), pp. 35-54. Berlin, De Gruyter Mouton.

[68] Boyd R., Borgerhoff-Mulder M., Durham W. H., Richerson P. J. 1997 Are cultural phylogenies possible. In Human by nature: Between biology and the social sciences (eds. Mitchell S. D., Richerson P. J., Maasen S., Weingart P.), pp. 355-386. Mahwah, NJ, Lawrence Erlbaum Associates.

[69] Greenhill S. J., Currie T. E., Gray, R. D. 2009 Does horizontal transmission invalidate cultural phylogenies? Proc. R. Soc. B 276, 2299-2306. (doi:10.1098/rspb.2008.1944)

[70] Nunn C. L., Mulder M. B., Langley S. 2006 Comparative methods for studying cultural trait evolution: a simulation study. Cross-Cult. Res. 40, 177-209. (doi:10.1177/1069397105283401)

[71] Foster G.M. 1976 Disease etiologies in non-western medical systems. Med.I Anthropol. 78, 773782.

[72] Hsu E., Harris S. (eds.) Plants, health and healing: On the interface of ethnobotany and medical anthropology. USA: Berhahn Books.

[73] Waldstein A., Adams C. 2006 The interface between medical anthropology and medical ethnobiology. J. Royal Anthropol. Inst. NS, S95-118.

[74] Greenwood B. 1981 Cold or spirits? Choice and ambiguity in Morocco's pluralistic medical system. Soc. Sci. Med. 15, 219-235.

[75] Obermeyer C. M. 2000 Pluralism and pragmatism: Knowledge and practice of birth in Morocco. Med. Anthropol. Q. 14, 180-201. 
[76] Teixidor-Toneu I., Martin G. J., Puri R. K., Ouhammou A., Hawkins J. A. 2017 Treating infants with frigg: Linking disease aetiologies, medicinal plant use and care-seeking behaviour in southern Morocco. J. Ethnobiol. Ethnomed. 13: 4. (doi:10.1186/s13002-016-0129-4)

[77] Thomas E., Vandebroek I., Van Damme P., Semo L., Noza Z. 2009 Susto etiology and treatment according to Bolivian Trinitario People: A "masters of the animal species" phenomenon. Medical Anthropology Quaterly. 23, 298-319.

[78] Ellen R., Puri R.K. 2016 Conceptualising 'core' medicinal floras: A comparative and methodological study of phytomedical resources in related Indonesian populations. Conserv. Soc. 14, 345-358.

[79] Shennan S. 2008. Canoes and cultural evolution. Proc. Natl Acad. Sci. 105(9), 3175-3176.

[80] Gairola S., Sharma J., Bedi Y. S. 2014 A cross-cultural analysis of Jammu, Kashmir and Ladakh (India) medicinal plant use. J. Ethnopharmacol. 155, 925-986.

[81] Molares S., Ladio A. 2009 Ethnobotanical review of the Mapuche medicinal flora: Use patterns on a regional scale. J. Ethnopharmacol. 122, 251-260.

[82] Collins S., Martins X., Mitchell A., Teshome A., Arnason J. T. 2006 Quantitative ethnobotany of two East Timorse cultures. Econ. Bot. 60, 347-361.

[83] Heinrich M., Ankli A., Frei B., Weimann C., Sticher O. 1998 Medicinal plants in Mexico: Healers' consensus and cultural importance. Soc. Sci. Med. 47, 1859-1871.

[84] Leporatti M. L., Ivancheva S. 2003 Preliminary comparative analysis of medicinal plants used in the traditional medicine of Bulgaria and Italy. J. Ethnopharmacol. 87, 123-142.

[85] Saslis-Lagoudakis C. H., Klitgaard B. B., Forest F., Francis L., Savolainen V., Williamson E. M., Hawkins J. A. 2011 The use of phylogeny to interpret cross-cultural patterns in plant use and guide medicinal plant discovery: an example from Pterocarpus. PLOS ONE 6, e22275.

[86] Saslis-Lagoudakis C. H., Savolainen V., Williamson E. M., Forest F., Wagstaff S. J., Baral S. R., Watson M. F., Pendry C. A., Hawkins J. A. 2012 Phylogenies reveal predictive power of traditional medicine in bioprospecting. Proc. Natl Acad. Sci. 109, 15835-15840.

[87] Yessoufou K., Daru B. H., Muasya A. M. 2014 Phylogenetic exploration of commonly used medicinal plants in South Africa. Mol. Ecol. Resour. (doi:10.1111/1755-0998.12310)

[88] Rønsted N., Savolainen V., Mølgaard P., Jäger A. K. 2008 Phylogenetic selection of Narcissus species for drug discovery. Biochem. Syst. Ecol. 36, 417-422.

[89] Zhu F., Qin C., Tao L., Liu X., Shi Z., Ma X., Jia J., Tan, Y., Cui C., Lin J., Tan, C., Jiang Y., Chen Y. 2011 Clustered patterns of species origins of nature-derived drugs and clues for future bioprospecting. Proc. Natl Acad. Sci. 108, 12943-12948.

[90] Souza E. N. F., Williamson E. M., Hawkins J. A. 2018 Which plants used in ethnomedicine are characterized? Phylogenetic patterns in traditional use related to research effort. Front. Plant Sci. doi: 10.3389/fpls.2018.00834

[91] Berlin B. 1973 Folk systematics in relation to biological classification and nomenclature. Annu. Rev. Ecol. Evol. Syst. 4, 259-271.

[92] Teixidor-Toneu I. 2017 The evolution of medicinal floras: Insights from Moroccan medicinal plant knowledge transmission. Doctoral dissertation. Reading, UK, University of Reading. 
[93] http://ehrafworldcultures.yale.edu/ehrafe/

[94] Hammarström H., Forkel R., Haspelmath M., Bank S. 2016 Glottolog 2.7. Max Planck Institute for the Science of Human History, Jena. http://glottolog.org

[95] Turchin P., Brennan R., Currie T. E., Feeney K. C., Francois P., Hoyer D., Manning J. G., Marciniak A., Mullins D., Palmisano A., Peregrine P., Turner E. A. L., Whitehouse H. 2015 Seshat: The Global History Databank Cliodynamics 6, 77-107.

[96] http://clld.org/datasets.html

[97] Albuquerque U. P., Soares Silva J., Almeida Campos J. L., Silva Sousa R., Silva T. C., Nóbrega Alves R. R. 2013 The current status of ethnobiological research in Latin America: gaps and perspectives. J Ethnobiol. Ethnomed. 9:72. doi:10.1186/1746-4269-9-72.

[98] Cámara-Leret R., Paniagua-Zambrana N., Balslev H., Macía M. J. 2014 Ethnobotanical knowledge is vastly under-documented in northwestern South America. PLOS ONE 9, e85794.

(doi:10.1371/journal.pone.0085794)

[99] Bennett B.C., Balick, M. J. 2014 Does the name really matter? The importance of botanical nomenclature and plant taxonomy in biomedical research. J. Ethnopharmacol. 152, 387-392.

[100] Rivera D., Allkin R., Obón C., Alcaraz F., Verpoorte R., Heinrich M. 2014 What is in a name? The need for accurate scientific nomenclature for plants. J. Ethnopharmacol. 152, 393-402.

[101] Heinrich M., Edwards S., Moerman D. E., Leonti M. 2009 Ethnopharmacological field studies: A critical assessment of their conceptual basis and methods. J.Ethnopharmacol. 124, 1-17.

[102] Souza E. N. F., Hawkins J. A. Comparison of herbarium label data and published medicinal use: Herbaria as an underutilized source of ethnobotanical information. Econ. Bot. 71(1), 1-12.

[103] Leonti M., Verpoorte R. 2017 Traditional Mediterranean and European herbal medicines. J. Ethnopharmacol. 199, 161-167. 
Table 1. Types of research questions regarding medicinal plant use that are enabled by PCMs. (A) and (B) - PCMs are used to examine cultural change while accounting for Galton's problem; (C) community phylogenetic methods to describe the overall similarity of ethnopharmacopoeias, and putative drivers of overall similarity identified.

\begin{tabular}{|c|c|}
\hline $\begin{array}{l}\text { (A) Mapping and ancestral state } \\
\text { reconstruction: how are ethnobotanical } \\
\text { features distributed across societies and how } \\
\text { often have they originated? }\end{array}$ & $\begin{array}{l}\text { Features might include use of specific plant } \\
\text { species, modes of application or preparation or } \\
\text { perceptions of plant properties. } \\
\text { - Was plant } X \text { adopted for medicinal use } \\
\text { once or multiple times? } \\
\text { - Has use of plants as fumigants } \\
\text { originated once or multiple times? } \\
\text { - Has the perception of the humoral } \\
\text { properties of plant } X \text { originated once or } \\
\text { or multiple times? }\end{array}$ \\
\hline $\begin{array}{l}\text { (B) Correlated evolution: do ethnobotanical } \\
\text { features evolve together? }\end{array}$ & $\begin{array}{l}\text { Features might include use of specific plant } \\
\text { species, healing techniques or illness } \\
\text { aetiologies. } \\
\text { - Do illness aetiologies (e.g., ritual } \\
\text { treatments) and specific treatments } \\
\text { (e.g., use of plants as fumigants) co- } \\
\text { evolve? } \\
\text { - Is there turnover in the use of plant } \\
\text { species but conservation of healing } \\
\text { techniques, or do they co-evolve? } \\
\text { Do ethnopharmacopoeias evolve as } \\
\text { systems, or are plants adopted } \\
\text { independent of any others? }\end{array}$ \\
\hline $\begin{array}{l}\text { (C) Community phylogenetics: what are the } \\
\text { drivers of overall similarity in the composition } \\
\text { of ethnofloras? }\end{array}$ & $\begin{array}{l}\text { Putative drivers could include any } \\
\text { quantitatively measurable factor that could be } \\
\text { used to create distance matrices, such as } \\
\text { floristic environment, proximity of peoples or } \\
\text { climate variables, or qualitative, intrinsic factors } \\
\text { such as belief systems. } \\
\text { - Can intrinsic factors, such as belief } \\
\text { systems, or extrinsic factors explain } \\
\text { similarity in ethnofloras? } \\
\text { - Do societies use similar or closely } \\
\text { related plants for similar therapeutic } \\
\text { applications? }\end{array}$ \\
\hline
\end{tabular}


Table 2. Four tests to determine the likely origins of plant use: phylogenetic, linguistic, use, and proximity. Considering any plant species and its use across ethnolinguistic groups of known relationship, these tests may discriminate different modes of transmission from independent discovery.

\begin{tabular}{|c|c|c|c|c|}
\hline $\begin{array}{l}\text { 1. Phylogenetic } \\
\text { (congruence) test }\end{array}$ & 2. Linguistic test & $\begin{array}{l}\text { 3. Plant use } \\
\text { test }\end{array}$ & $\begin{array}{l}\text { 4. Geographic } \\
\text { proximity test }\end{array}$ & $\begin{array}{l}\text { RELATIONSHIP } \\
\text { Origin of plant } \\
\text { use }\end{array}$ \\
\hline $\begin{array}{l}\text { Use is a derived } \\
\text { character shared } \\
\text { amongst related } \\
\text { groups }\end{array}$ & $\begin{array}{l}\text { Plant names are } \\
\text { cognates }\end{array}$ & Shared & Usually close & $\begin{array}{l}\text { Ancestry } \\
\text { (vertical } \\
\text { transmission) }\end{array}$ \\
\hline $\begin{array}{l}\text { Use does not } \\
\text { characterise a } \\
\text { monophyletic } \\
\text { ethnolinguistic } \\
\text { group }\end{array}$ & $\begin{array}{l}\text { Plant names } \\
\text { unrelated or } \\
\text { cognates }\end{array}$ & Not shared & Usually distant & $\begin{array}{l}\text { Independent } \\
\text { Discovery } \\
\text { (convergence) }\end{array}$ \\
\hline $\begin{array}{l}\text { Use does not } \\
\text { characterise a } \\
\text { monophyletic } \\
\text { ethnolinguistic } \\
\text { group }\end{array}$ & $\begin{array}{l}\text { Plant names are } \\
\text { identified } \\
\text { loanwords }\end{array}$ & Shared & Close proximity & $\begin{array}{l}\text { Cultural } \\
\text { Diffusion } \\
\text { (horizontal } \\
\text { transmission) }\end{array}$ \\
\hline
\end{tabular}



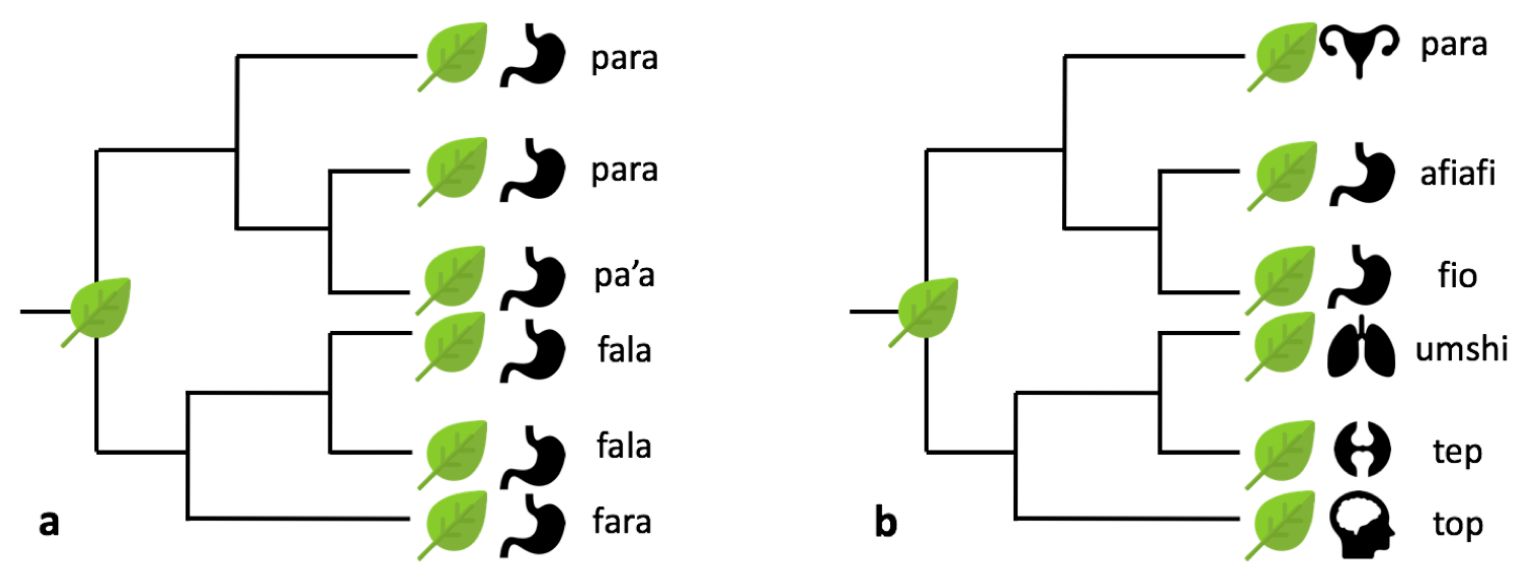

Figure 1. The medicinal use of a plant species by several linguistically related societies. The independently-derived phylogeny represents relationships between ethnolinguistic groups. The icons show whether each ethnolinguistic group uses a plant species or not (here, the leaf icon indicates the use of one single species) and the therapeutic applications (icons for body systems represent therapeutic applications) Vernacular names for the species are given. Ancestral reconstruction in both cases shows that the use is a derived character shared amongst related groups and that therefore the phylogenetic (congruence) test is passed. (a) Shows a scenario where both therapeutic application (use test) and the vernacular name of the plant species (linguistic test) have been conserved through time. Scenario (b) represents linguistic divergence and divergence in therapeutic application. 